\title{
Biochemical and Genetic Studies with Regulator Mutants of the Pseudomonas aeruginosa 8602 Amidase System
}

\author{
By W. J. BRAMMAR*, PATRICIA H. CLARKE AND A. J. SKINNER \\ Department of Biochemistry, University College, London, W.C. 1
}

(Accepted for publication 14 November 1966)

\begin{abstract}
SUMMARY
Mutants of Pseudomonas aeruginosa strain 8602 were isolated which were unable to produce an aliphatic amidase (acylamide amidohydrolase, EC 3.5.1.4) and could not grow on acetamide as a carbon or nitrogen source. Amidase-constitutive mutants, producing amidase in the absence of inducing amides, were isolated by selection on succinate + formamide agar. Sixteen mutants were magno-constitutive non-inducible mutants producing amidase at about the same rate or greater than the fully induced wild-type strain. Amidase synthesis in one magno-constitutive mutant was repressed by the non-substrate inducer $N$-acetylacetamide, but the others were not affected in any way. Six mutants were semi-constitutive, producing amidase at 10 $50 \%$ of the rate of the magno-constitutive mutants and were induced by $\mathrm{N}$-acetylacetamide. Most of the constitutive mutants were very sensitive to catabolite repression by succinate in pyruvate medium, but succinate produced only partial repression of one magno-constitutive mutant and three semiconstitutive mutants; one semi-constitutive mutant was not repressed except in the presence of inducer.

Six mutants isolated from succinate + formamide agar had altered inducer specificity and were induced to form amidase by formamide, which is a very poor inducer for the wild-type strain. The formamide-inducible mutants were also sensitive to catabolite repression by succinate although one mutant was only partially repressed.

Phage F 116 was used to transduce the amidase structural and regulator genes. In crosses between constitutive mutants of Pseudomonas aeruginosa as donors and amidase-negative mutants as recipients, the two characters were co-transduced with frequencies of $80-100 \%$. Similarly, in crosses between formamide-inducible and amidase-negative mutants these two characters were co-transduced with frequencies of $89-96 \%$. The amidase structural and regulator genes are considered to be closely linked.
\end{abstract}

\section{INTRODUCTION}

The aliphatic amidase (acylamide amidohydrolase, EC 3.5.1.4) produced by Pseudomonas aeruginosa 8602 is induced by growth in the presence of several substrate and non-substrate amides (Kelly \& Clarke, 1962; Brammar \& Clarke, 1964). Exponentially growing cultures synthesize the enzyme at a constant differential rate following a lag of about one generation after the addition of either acetamide (substrate inducer) or $\mathrm{N}$-acetylacetamide (non-substrate inducer). Enzyme synthesis is repressed by certain acetamide analogues, e.g. cyanoacetamide and thioacetamide. Amidase synthesis is also subject to catabolite repression by propionate, acetate,

* Present address: Department of Biological Sciences, Stanford University, Palo Alto, California, U.S.A. 
succinate and some other metabolites (Brammar \& Clarke, 1964). Amidase-negative mutants, which are unable to grow with acetamide as a carbon + nitrogen source, have been isolated after treating the wild-type strain with mutagenic agents (Skinner \& Clarke, 1965). The genetic character for amidase production can be transferred by phage-mediated transduction using phage F 116 isolated by Holloway, Egan \& Monk (1960). Constitutive mutants which produce amidase in the absence of inducer have been isolated (Clarke \& Brammar, 1965), and the genetic character for constitutivity can also be transferred by phage F 116. We have examined the kinetics of enzyme synthesis for a number of the constitutive mutants and other regulator mutants with altered inducibility, and used phage transduction to investigate the linkage of the amidase structural and regulator genes. A brief report of part of this work has appeared previously (Clarke \& Brammar, 1965).

Stanier, Palleroni \& Doudoroff (1966) reported that $90 \%$ of Pseudomonas aeruginosa strains can grow on acetamide and it seems probable that they all produce similar amidases.

\section{METHODS}

Organism. The parent strain was originally obtained from the National Collection of Type Cultures as Pseudomonas aeruginosa NCTC 8602. It was subcultured repeatedly in an acetamide-containing medium to enhance the acetamidase activity and the culture obtained was referred to as strain 8602/A (Kelly \& Clarke, 1962). The National Collection have now discarded NCTC 8602 so that it can no longer be confused with our strain which we now refer to as $P$. deruginosa strain 8602 . Constitutive mutants are referred to as mutants $\mathrm{C} 1$ etc.; amidase-negative mutants as mutants Am 1 etc.; formamide-inducible mutants as mutants F 1 etc. The pseudomonad phage F 116 isolated by Holloway et al. (1960) was kindly provided by Dr B. Holloway.

Maintenance of cultures. Stock cultures were maintained on slopes of nutrient agar prepared from Oxoid Nutrient Broth no. 2 powder and containing Oxoid no. 3 agar $(1.2 \%, \mathrm{w} / \mathrm{v})$. The stock cultures were stored at $4^{\circ}$ and mutant strains were lyophilized as soon as possible after isolation and identification.

Media for enzyme synthesis experiments. The media were based on the minimal salt medium described by Brammar \& Clarke (1964). The differential rates of amidase synthesis and the inducibility ratios were measured in minimal salt medium containing $1 \%(\mathrm{w} / \mathrm{v})$ sodium succinate. Catabolite repression by succinate was measured in minimal salt medium containing $1 \%(\mathrm{w} / \mathrm{v})$ sodium pyruvate. Acetamide medium was prepared by adding a solution of acetamide sterilized by membrane filtration to the minimal salt medium to give a final concentration of $0.5 \%(\mathrm{w} / \mathrm{v})$.

Medium for plating out cultures. The minimal salt medium was used with $1.2 \%(\mathrm{w} / \mathrm{v})$ Oxoid no. 3 or Difco Noble agar. Carbon and nitrogen sources were added as follows for succinate agar (S plates) $1 \%(\mathrm{w} / \mathrm{v})$ sodium succinate; $0.1 \%(\mathrm{w} / \mathrm{v})$ ammonium sulphate; for acetamide agar (AM plates) $0.5 \%(\mathrm{w} / \mathrm{v})$ acetamide; for succinate + formamide agar ( $\mathrm{S} / \mathrm{F}$ plates) $1 \%(\mathrm{w} / \mathrm{v})$ sodium succinate $+0.1 \%(\mathrm{v} / \mathrm{v})$ formamide; for succinate + formamide + cyanoacetamide agar (S/F/CN plates) $1 \%(\mathrm{w} / \mathrm{v})$ sodium succinate $+0.05 \%(\mathrm{v} / \mathrm{v})$ formamide $+1 \%(\mathrm{w} / \mathrm{v})$ cyanoacetamide; for succinate + lactamide agar (S/L plates) $1 \%(\mathrm{w} / \mathrm{v})$ sodium succinate $+0.02 \%(\mathrm{w} / \mathrm{v})$ lactamide.

Dilution buffer. Before plating, the bacteria were resuspended and diluted in buffer pH 7.2 containing $\left(\%\right.$, w/v): $0.3 \mathrm{KH}_{2} \mathrm{PO}_{4}, 0.7 \mathrm{Na}_{2} \mathrm{HPO}_{4}, 0.4 \mathrm{NaCl}$ and $0.02 \mathrm{MgSO}_{4}$. 
Growth conditions. Cultures were grown for enzyme experiments in conical flasks of capacity 10 times that of the medium volume and shaken at $37^{\circ}$ on a mechanical shaker. The culture medium was inoculated with 1/20 of its volume of an overnight culture in the same medium. Experiments on the rates of enzyme synthesis were started when the culture had become established in the exponential growth phase.

Growth measurements. The optical extinctions of the cultures were measured at $670 \mathrm{~m} \mu$ with a Unicam SP 600 spectrophotometer. A standard curve was used to convert the readings to dry wt. bacteria.

Enzyme assays. Amidase activity was measured by the hydroxamate method for transferase activity described by Brammar \& Clarke (1964). The substrate mixture contained $100 \mathrm{~mm}$-acetamide, $500 \mathrm{~mm}$-hydroxylamine hydrochloride, freshly neutra-

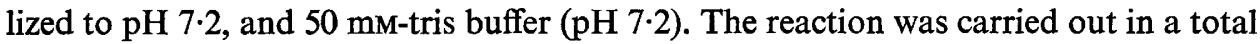
volume of $1 \mathrm{ml}$. and enzyme samples for assay were $0.5-0.25 \mathrm{ml}$. The reaction mixture was incubated in a water bath at $37^{\circ}$; the time of incubation was varied between 5 and $20 \mathrm{~min}$. according to the activity of the sample. The specific activity was defined as $\mu$ moles acethydroxamate produced/mg. dry wt. bacteria/min.

Amides. Acetamide was obtained from Hopkin and Williams Ltd. and recrystallized twice from ethanol. $N$-acetylacetamide was prepared by refluxing acetamide with excess acetic anhydride, removing the residual acetic anhydride by distillation and twice recrystallizing the product from ethylmethyl ketone. Cyanoacetamide was obtained from Hopkin and Williams Ltd. and purified by recrystallizing twice from methanol. Lactamide, prepared by ammoniolysis of lactide, was a gift from Dr P. Draper. Formamide was stored in the dark.

Reagents. Hydroxylamine hydrochloride was recrystallized 3 times from distilled water. Tris (2-amino-2-hydroxymethylpropane-1,3-diol) was recrystallized twice from methanol + water $(20+1$ by vol). Ethylmethane sulphonate (EMS) was obtained from Kodak Ltd., London. $N$-methyl- $N^{\prime}$-nitro- $N$-nitrosoguanidine (NMG) was obtained from the Aldrich Chemical Co.

Mutagenic treatment: ethylmethane sulphonate (EMS) as mutagen. EMS was added to a $5 \mathrm{hr}$ culture of wild-type strain 8602 growing either in nutrient broth or succinate medium to give a final concentration of $160 \mathrm{mM}$. The culture was incubated at $37^{\circ}$ for $15 \mathrm{~min}$. or at room temperature for $1 \mathrm{hr}$, centrifuged, the deposit washed twice and resuspended in dilution buffer.

$N$-methyl-N'-nitro- $N$-nitrosoguanidine $(N M G)$ as mutagen. $\mathrm{NMG}$ was added at a final concentration of $200 \mu \mathrm{g} . / \mathrm{ml}$. to a $5 \mathrm{hr}$ nutrient broth culture of the wild-type strain resuspended in $100 \mathrm{~mm}$ citrate buffer $(\mathrm{pH} \mathrm{6.0)}$ ). The cultures were incubated for $75 \mathrm{~min}$. at room temperature $(0 \cdot 1 \%$ survival $)$, centrifuged, the deposit washed twice and resuspended in dilution buffer.

Ultraviolet irradiation. Bacteria from a $5 \mathrm{hr}$ broth culture were resuspended in dilution buffer and irradiated at $2537 \AA(95 \%)$ for $2 \mathrm{~min}$. at a distance of $12 \mathrm{~cm}$. $\left(\mathrm{I}=854 \mathrm{ergs} / \mathrm{cm}^{2} / \mathrm{sec}\right.$.). These conditions gave about $0.1 \%$ survival.

Selection of mutants. To obtain amidase-negative $\left(\mathrm{Am}^{-}\right)$mutants, $0 \cdot 1 \mathrm{ml}$. samples of treated bacteria were inoculated into nutrient broth, grown overnight, diluted to give $10^{3}$ bacteria $/ \mathrm{ml}$. and $0 \cdot 1 \mathrm{ml}$. spread on each of about 60 plates. Amidase-negative mutants were selected as small colonies on acetamide plates, or acetamide plates supplemented with $0.001 \%(\mathrm{w} / \mathrm{v})$ sodium succinate.

Regulator mutants were obtained by plating about $10^{8}$ bacteria on $\mathrm{S} / \mathrm{F}$ plates either 
immediately after mutagenic treatment, or after overnight growth in nutrient broth. The mutants grew as large colonies from a faint background growth of wild-type bacteria. These colonies were picked off, grown overnight in succinate medium and tested for amidase activity. To eliminate wild-type bacteria, the mutant cultures were replated on $\mathrm{S} / \mathrm{F}$ plates to give about 20 colonies/plate, and single mutant colonies isolated.

Preparation of phage lysates. The preparation of high-titre lysates of phage F 116 followed the method of Adams (1959). A broth culture of bacteria was mixed with phage, and $0.2 \mathrm{ml}$. samples containing $3 \times 10^{8}$ bacteria and $10^{6}-10^{7}$ plaque forming units (p.f.u.) were spread on each nutrient agar plate. Incubation for $18 \mathrm{hr}$ at $37^{\circ}$ resulted in confluent lysis. The phage was harvested in TNM buffer ( $\mathrm{pH} 7 \cdot 1$ ), consisting of $10 \mathrm{~mm}$-tris, $10 \mathrm{~mm}$-magnesium sulphate and $150 \mathrm{~mm}$-sodium chloride. Phage stocks were sterilized by adding chloroform, after low-speed centrifugation to remove bacterial debris, and stored at $4^{\circ}$. They were assayed by the agar layer technique. The transducing phage was propagated twice in the donor strain to eliminate the wild-type phage particles. This method consistently produced $10^{10}-10^{11}$ p.f.u./ml.

Transduction. The procedure for transduction followed that of Holloway, Monk, Hodgins \& Fargie (1962). Recipient bacteria were grown overnight in nutrient broth, centrifuged down and resuspended in dilution buffer to give $2-4 \times 10^{9}$ bacterial $/ \mathrm{ml}$. Samples $(1 \mathrm{ml}$.) were mixed with $1 \mathrm{ml}$. phage suspension at a multiplicity of 5 to 10 . After $60 \mathrm{~min}$. at $37^{\circ}$ for phage adsorption, the bacteria were centrifuged down and resuspended in $2 \mathrm{ml}$. dilution buffer. Samples $(0.2 \mathrm{ml}$.), diluted when necessary, were spread over the surface of agar plates to give 100 to 150 transductants/plate after 48-72 hr incubation at $37^{\circ}$. Controls were included to detect reversion of recipient bacteria, by plating $0.1 \mathrm{ml}$. samples of resuspended bacteria on appropriate media. In addition, $0.1 \mathrm{ml}$. samples of phage were plated on nutrient agar to detect viable bacteria in the phage stock.

Replica plating. Transductants were replicated after $72 \mathrm{hr}$ incubation according to Lederberg \& Lederberg (1952).

\section{RESULTS}

\section{Isolation of regulator mutants}

A method was devised which depended on using a non-inducing amide as a growth substrate so that any constitutive mutants would have a selective advantage over the wild-type strain. The most suitable amide for this purpose was formamide, but as this strain of Pseudomonas aeruginosa is unable to grow with one-carbon compounds as sole carbon source, the medium contained succinate as carbon source and formamide as nitrogen source (S/F plates). The wild-type strain produced only faint shadowy growth on this medium so that the mutants appeared as large colonies growing out of a background haze.

The specific activities of the mutant cultures after overnight growth in succinate medium varied over a wide range. Some mutants behaved like the wild-type parent and produced little or no amidase activity while others produced as much enzyme as a fully induced wild-type culture. This procedure therefore appeared to select not only constitutive mutants but also a class of inducible mutants which, unlike the parent 
wild-type, were able to grow on $\mathrm{S} / \mathrm{F}$ plates. Spontaneous mutation to allow growth on $S / F$ plates occurred in $1 / 10^{7}$ to $1 / 10^{6}$ bacteria and the rate was increased by mutagenic treatment.

\section{Properties of constitutive mutant $C 1$}

The first constitutive mutant identified was compared with the wild-type strain with respect to growth rate and factors affecting the rate of amidase synthesis. There was no significant difference in the growth rates of the two cultures in nutrient broth or minimal salt media. In succinate medium the differential rate of amidase synthesis was equal to or slightly greater than that of the fully induced wild type.
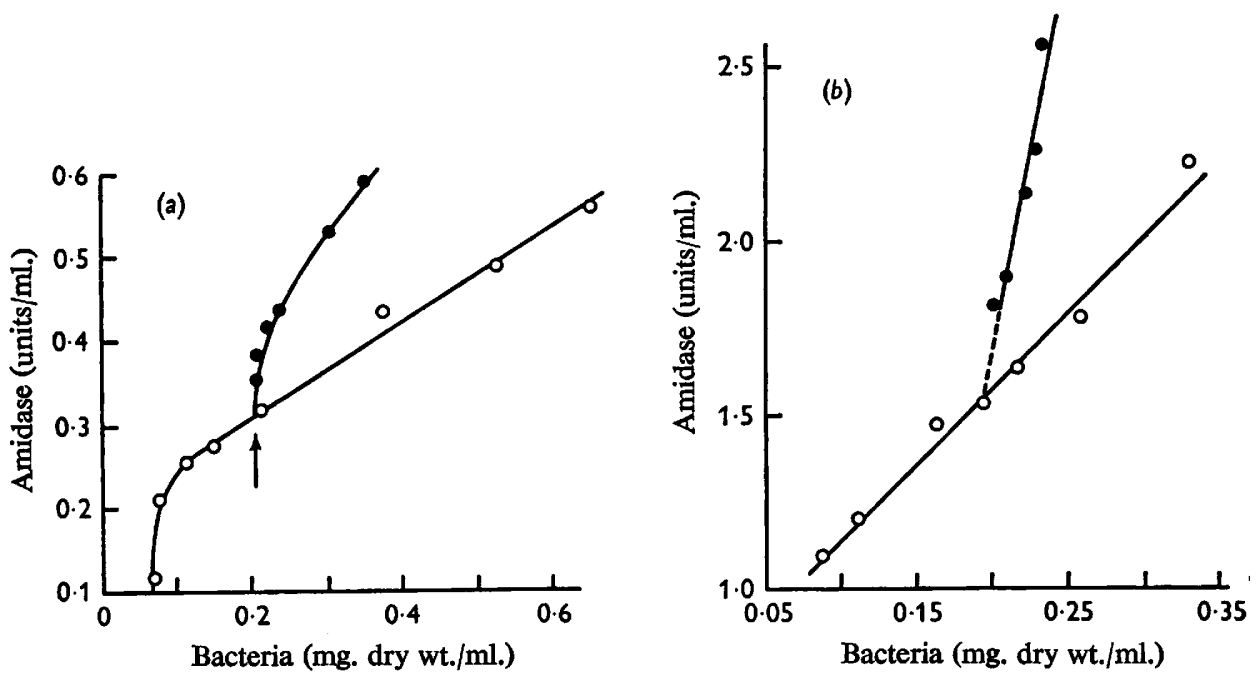

Fig. 1a. The effect of azide on amidase synthesis by the wild-type strain of Pseudomonas aeruginosa 8602 . - 2 mM-sodium azide added at the point indicated by arrow; $\mathrm{O}-\mathrm{O}$, control culture; acetate medium used for experiment.

Fig. $1 \mathrm{~b}$. The effect of azide on amidase synt hesis by the constitutive mutant of Pseudomonas aeruginosa $8602 \mathrm{C} 1$. -, $5 \mathrm{~mm}$-sodium azide added at point indicated by arrow; $\mathrm{O}-\mathrm{O}$, control culture; succinate medium used for experiment.

One of the characteristic features of amidase synthesis by the wild type in acetamide medium was the second phase of enzyme synthesis as the culture reached the end of exponential growth (Kelly \& Kornberg, 1962). This late-phase synthesis was also found with acetate as the growth substrate but with no other carbon source tested. Amidase synthesis in acetate medium occurred earlier when the $\mathrm{pH}$ value of the medium was allowed to increase. This effect appeared to be related to a decrease in the growth rate and was also produced by the addition of sodium azide to an exponnentially growing culture. In the experiment shown in Fig. $1 a$ the growth rate was decreased by about $40 \%$ and there was marked stimulation of the differential rate of amidase synthesis. The constitutive mutant $\mathrm{C} 1$ synthesized amidase at a constant differential rate during exponential growth in succinate medium but there was a marked increase in the rate of enzyme synthesis towards the end of the growth period. Figure $1 b$ shows the effect of azide on amidase synthesis during exponential growth. In this experiment it produced a 4-fold decrease in the growth rate and a 4-fold 
increase in the differential rate of amidase synthesis, so that the absolute rate was unaffected.

The non-substrate inducer $N$-acetylacetamide was used to test mutant $\mathrm{C} 1$ for inducibility. At a concentration of $10 \mathrm{~mm}$, which is saturating for induction of the wildtype strain, it had no effect on amidase synthesis by mutant $\mathrm{C} 1$ at any stage of growth. Mutant C 1 therefore behaved as a fully constitutive or non-inducible strain. According to the classification proposed by Collins et al. (1965) it could be described as a strictly constitutive magno-constitutive strain, since it produced amidase at about the same rate as the fully induced wild-type strain in the presence or absence of inducer.

Many normal cell metabolites can cause catabolite repression of amidase synthesis by the wild-type strain. Acetate and propionate repress amidase induction by acetamide or $N$-acetylacetamide in succinate medium (Brammar \& Clarke, 1964). Succinate

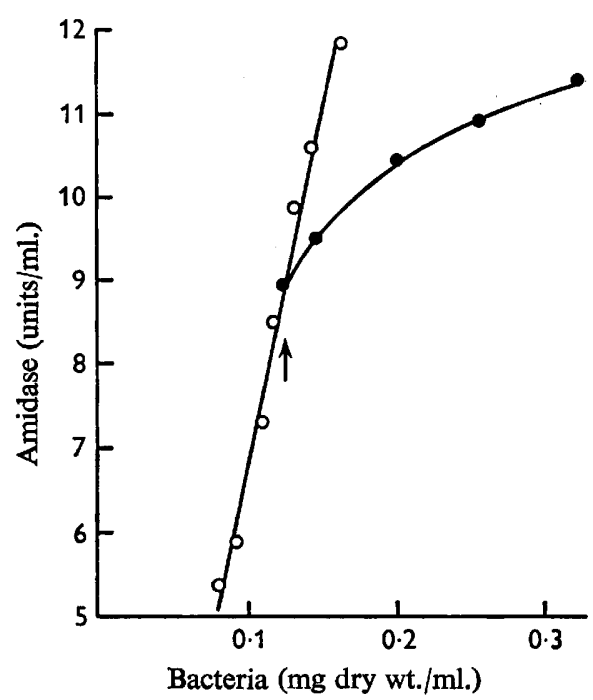

Fig. 2

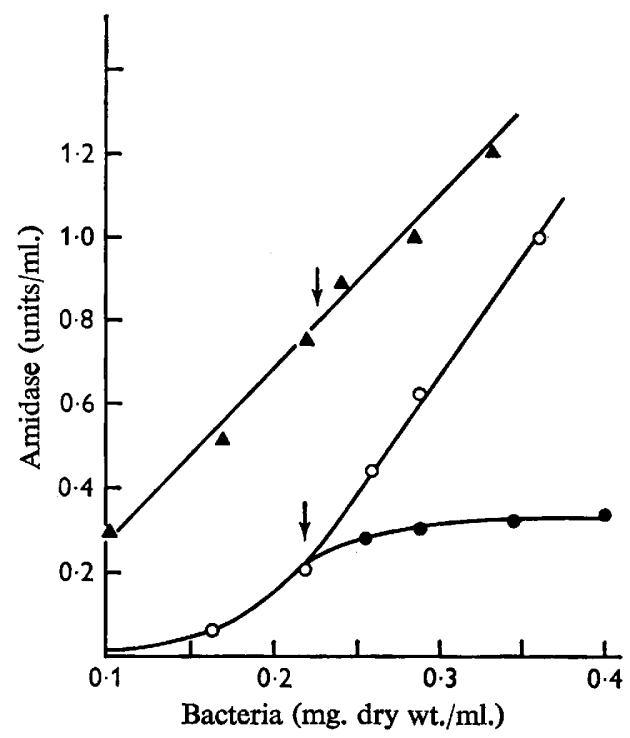

Fig. 3

Fig. 2. Catabolite repression by succinate of amidase synthesis by the constitutive mutant of Pseudomonas aeruginosa $8602 \mathrm{C} 1$. - $-10 \mathrm{mM}$-sodium succinate added at point indicated by arrow; $\mathrm{O}-\mathrm{O}$ control culture; pyruvate medium used for experiment.

Fig. 3. Effect of cyanoacetamide on amidase synthesis by constitutive and wild-type strains of Pseudomonas aeruginosa 8602 . Wild-type strain induced with $10 \mathrm{~mm}-N$-acetylacetamide; - $-10 \mathrm{~mm}$-cyanoacetamide added at point indicated by arrow; $\mathrm{O}-\mathrm{O}$, control culture; $\Delta-\Delta$, mutant $C 110 \mathrm{~mm}$-cyanoacetamide added at point indicated by arrow.

also exerts catabolite repression, e.g. amidase induction by $10 \mathrm{~mm}-N$-acetylacetamide in pyruvate medium is $98-100 \%$ repressed by the addition of $10 \mathrm{~mm}$ succinate to growing cultures. Figure 2 shows that mutant $\mathrm{C} 1$ growing in pyruvate medium was like the wild-type strain, very sensitive to repression by succinate.

We had concluded previously from experiments with growing cultures (Brammar \& Clarke, 1964) and carbon-starved bacteria (Clarke \& Brammar, 1964) that the amide analogue cyanoacetamide repressed amidase synthesis by competing with the inducer for an amide-specific binding site. It has now been shown (Brammar, McFarlane \& Clarke, 1966) that competition for a permease is not involved since cyanoacetamide 
had no effect on the uptake of ${ }^{14} \mathrm{C}$-labelled $N$-acetylacetamide at a concentration which prevented amidase induction. If the site of competition of the amides is the inducerbinding site of a cytoplasmic repressor molecule it could be predicted that at least some of the constitutive mutants would be unaffected by the amide analogue. Figure 3 shows that $10 \mathrm{~mm}$-cyanoacetamide almost completely repressed amidase synthesis by an induced wild-type culture and had no effect on the synthesis of amidase by mutant $\mathrm{C} 1$.

\section{Survey of constitutive mutants}

The constitutive mutant $\mathrm{C} 1$ had been tested in considerable detail to compare it with the wild-type strain. Similar but slightly simplified methods were used to examine the other regulator mutants. The enzyme studies were carried out with exponentially growing cultures and about 5 samples were taken over a period of $1.5-2.5 \mathrm{hr}$, depending on the growth conditions.

Differential rates of amidase synthesis. The measurements were made in succinate medium and were calculated as a percentage of the rate for mutant $C 1$. There was some variation in the rate of amidase synthesis by mutant $\mathrm{C} 1$ in different experiments which was thought to be due to slight variations in the growth conditions. Each mutant culture was therefore tested in parallel with mutant $\mathrm{C} 1$. Several mutants were tested on two or three occasions and gave results agreeing within $5 \%$. Figure 4 shows a typical experiment and compares the differential rates of amidase synthesis by mutants $C 8$, C 11, C 20 with mutants $C 1$. The results for 22 constitutive mutants tested are given in Table 1. Most of these mutants had a differential rate of amidase synthesis in succinate medium within $80-120 \%$ of that of $\mathrm{C} 1$. A few had higher rates; $\mathrm{C} 11$ and $\mathrm{C} 24$ were the highest with a rate of 165,6 mutants had significantly lower rates ranging from $10 \%$ to $50 \%$ of that of $\mathrm{C} 1$.

Inducibility. Preliminary experiments compared the specific activities of organisms grown overnight in succinate medium with those of organisms grown in succinate medium containing $10 \mathrm{mM}-N$-acetylacetamide as non-substrate inducer. The results suggested that the mutants with high differential rates of amidase synthesis like $\mathrm{C} 1$ were not induced to form more amidase in the presence of $N$-acetylacetamide, but that some of the mutants with low differential rates were partially inducible. This was investigated further by using exponentially growing cultures. Soon after the cultures had reached the exponential growth phase they were divided into two parts to one of which $N$-acetylacetamide was added to a concentration of $10 \mathrm{~mm}$. The results are summarized in Table 1 . The constitutive mutants with differential rates of amidase synthesis which were $80 \%$ or more of that of $\mathrm{C} 1$ were not induced to synthesize amidase at an increased rate by $N$-acetylacetamide. They therefore behaved as fully constitutive or non-inducible strains. Mutant C 24 was unusual in that amidase synthesis was repressed $68 \%$ by $10 \mathrm{mM}-N$-acetylacetamide.

The six constitutive mutants with lower differential rates of amidase synthesis were all inducible, i.e. semi-constitutive. The inducibility ratio was calculated as

$$
\frac{\text { rate of amidase synthesis with } 10 \mathrm{~mm}-N \text {-acetylacetamide }}{\text { rate of amidase synthesis without inducer }} \text {. }
$$

The values obtained were mostly 2 to 3 ; mutant $C 9$ with a differential rate of 10 to 14 had an inducibility ratio of 9 , but this culture could be clearly distinguished from the wildtype strain which had an inducibility ratio of $>100$ under these conditions. 
Catabolite repression. Mutant $\mathrm{C} 1$ had been found to be almost as sensitiveas the wildtype strain to catabolite repression by succinate in pyruvate medium. Similar experiments were done with the other constitutive mutants. All but one of the magnoconstitutive mutants were repressed $80-90 \%$ by $10 \mathrm{~mm}$-succinate. C 24 was again the exception among the magno-constitutive mutants and was only repressed by $63 \%$.

Table 1. Properties of amidase constitutive mutants of Pseudomonas aeruginosa 8602

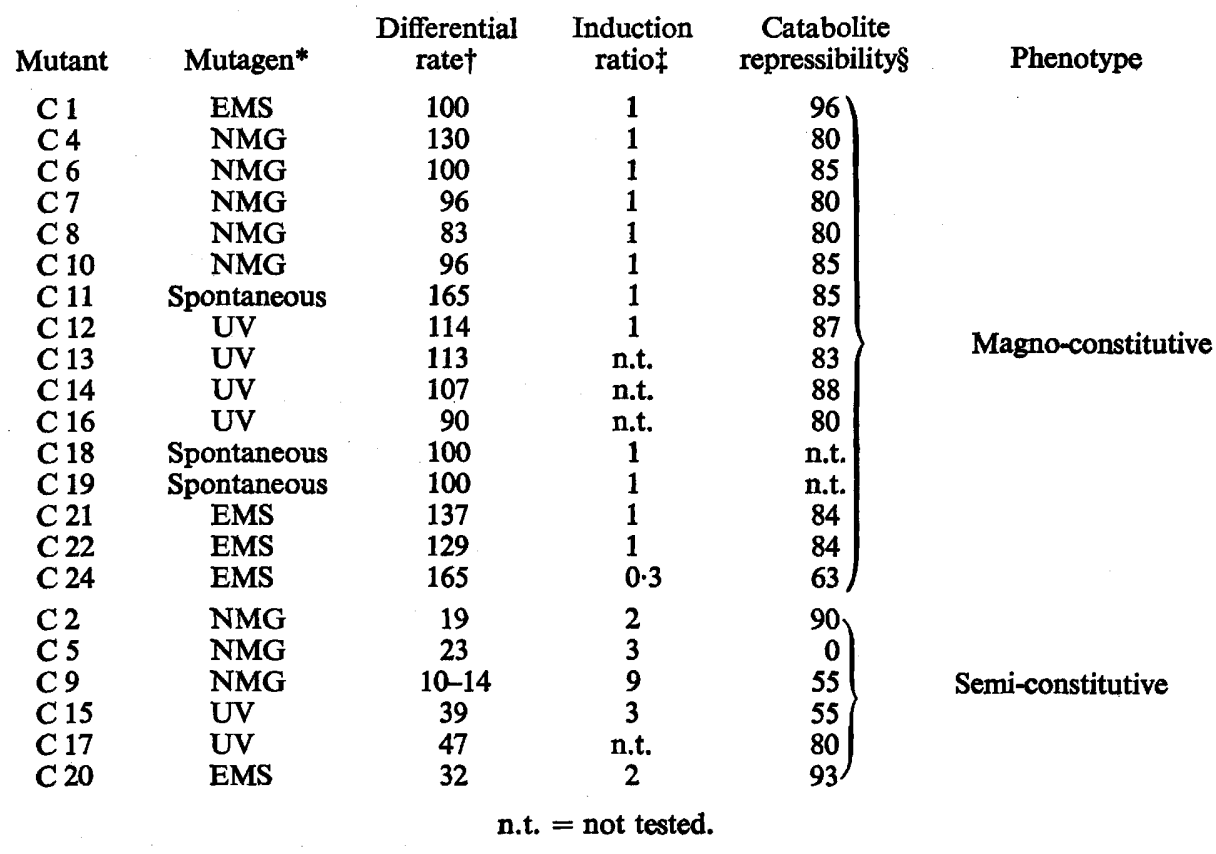

* Mutagens. EMS = ethylmethane sulphonate; NMG $=N$-methyl- $N^{\prime}$-nitro- $N$-nitrosoguanidine, $\mathrm{UV}=$ ultraviolet irradiation.

$\dagger$ Differential rate: the rate of amidase synthesis/mg. bacterial growth for mutant $\mathrm{C} 1$ in succinate medium was assigned a value of 100 . The results for all other mutants are expressed as a percentage of that for $\mathbf{C} 1$.

¥ Induction ratio: the differential rate of amidase synthesis in succinate medium containing $10 \mathrm{~mm}-N$-acetylacetamide/rate of synthesis in the absence of inducer.

$\S$ Catabolite repressibility: the percentage repression of the rate of amidase synthesis in pyruvate medium in the presence of 10 mM-sodium succinate.

The semi-constitutive mutants were more variable in their sensitivity to catabolite repression. C 2, C 17 and $\mathrm{C} 20$ were as sensitive to catabolite repression as the magnoconstitutivemutants, but mutants $\mathrm{C} 9$ and $\mathrm{C} 15$ were repressed only $55 \%$ and $\mathrm{C} 5$ was not repressed at all. The semi-constitutive mutants repressible by succinate synthesized amidase constitutively in pyruvate medium at least three times faster than in succinate medium, but the rate of amidase synthesis by $\mathrm{C} 5$ was the same in both media. With $10 \mathrm{mM}-N$-acetylacetamide added as inducer in pyruvate medium, the total rate of amidase synthesis by mutant C 5 (constitutive+induced) was repressed by $56 \%$. 


\section{Formamide-inducible mutants}

The mutants isolated from S/F plates which did not produce amidase constitutively nevertheless required amidase for growth, since formamide was the only nitrogen source provided in the medium. It seemed likely that these mutants differed from the wild type in being induced by formamide. They were grown overnight in liquid succinate medium containing $0 \cdot 1 \%(\mathrm{w} / \mathrm{v})$ formamide and were found to produce low but detectable amounts of amidase. When the induction rates were measured with growing cultures and formamide, acetamide or propionamide as inducers, the mutants differed from the wild type in their inducibility patterns for the three amides. There

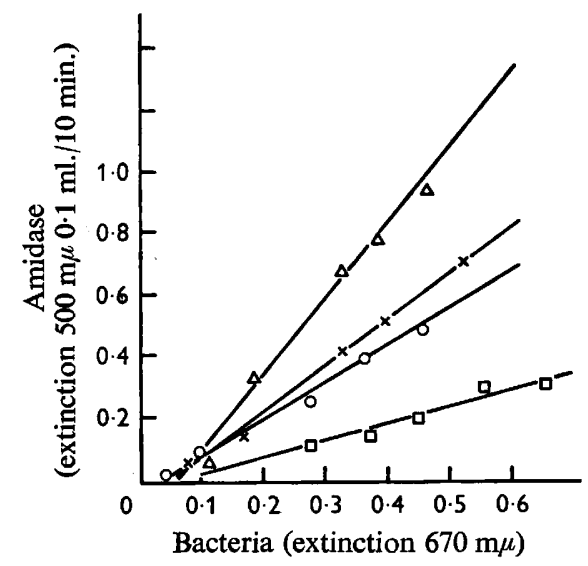

Fig. 4

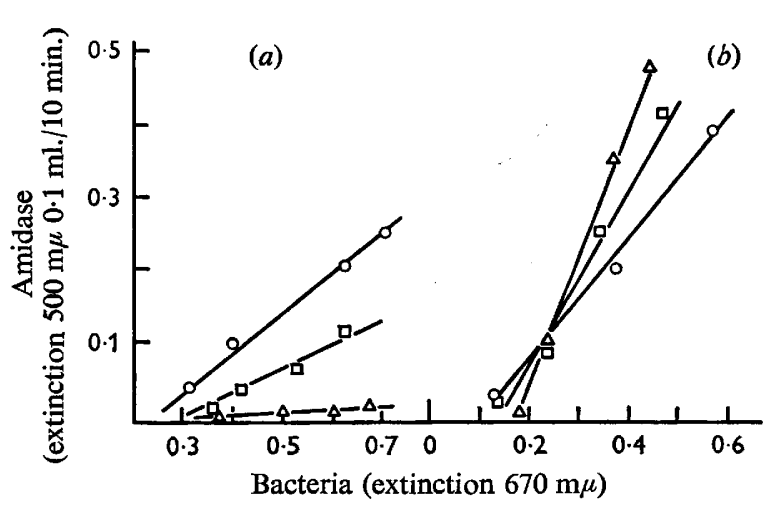

Fig. 5

Fig. 4. Differential rates of amidase synthesis by constitutive strains of Pseudomonas aeruginosa 8602. $\times-\times$, Strain C 1; $\bigcirc-O$, strain C 8; $\square-\square$, strain C 20; $\triangle-\triangle$, strain C 11 .

Fig. 5. Induction of amidase synthesis by formamide $(\triangle-\triangle)$, acetamide $(\mathrm{O}-\mathrm{O})$ and propionamide $(\square-\square)$, with $(a)$ the wild-type strain and $(b)$ mutant $F_{6}$. Amides added at $10 \mathrm{~mm}$ in succinate medium.

was no significant difference in the basal rate of amidase synthesis in the absence of inducer between the wild type and any of the F mutants. Although it had previously been thought from experiments with cultures grown overnight that formamide was not an inducer (Kelly \& Clarke, 1962), these experiments showed that it had weak inducing activity for the wild-type strain and significantly higher inducing activity for all these mutant strains. Figure 5 compares the differential rates of amidase induction by the three amides for the wild-type and mutant F 6 which had the most marked alteration in amide inducibility pattern. It can be seen that for this mutant formamide was a more effective inducer than acetamide under these conditions. The results for all the $\mathrm{F}$ mutants tested are given in Table 2.

Since formamide is a weak inducer for the wild-type strain it would be more effective in succinate medium if a mutation occurred which resulted in a decreased sensitivity to catabolite repression by succinate. Although the previous experiments suggested that the $F$ mutants had mutations which affected the inducer specificity, it was thought that catabolite repressibility could have been altered at the same time. The cultures were induced with $\mathrm{N}$-acetylacetamide in pyruvate medium and tested for 
catabolite repression by $10 \mathrm{~mm}$-succinate. The results (Table 2 ) showed that although the sensitivity to catabolite repression of these strains was less than that of the wild type the differences were not very great, except for mutant F 6 which was only $60 \%$ repressed.

Table 2. Properties of formamide-inducible mutants of Pseudomonas aeruginosa 8602

\begin{tabular}{|c|c|c|c|c|}
\hline \multirow[b]{3}{*}{$\begin{array}{l}\text { Mutant } \\
\text { strain }\end{array}$} & \multicolumn{3}{|c|}{ Inducer } & \multirow{3}{*}{$\begin{array}{l}\text { Catabolite } \\
\text { repressibility } \dagger\end{array}$} \\
\hline & \multirow{2}{*}{\multicolumn{3}{|c|}{$\begin{array}{l}\text { Formamide Acetamide Propionamide } \\
\text { Rate of amidase induction* }\end{array}$}} & \\
\hline & & & & \\
\hline Wild type & 0.3 & $4 \cdot 2$ & $2 \cdot 2$ & $98-100$ \\
\hline F 1 & $3 \cdot 8$ & 4.9 & $7 \cdot 5$ & 60 \\
\hline F 2 & $3 \cdot 1$ & $6 \cdot 4$ & $4 \cdot 8$ & 84 \\
\hline F 5 & $1 \cdot 2$ & $3 \cdot 2$ & $2 \cdot 2$ & 86 \\
\hline F 6 & 10 & $4 \cdot 7$ & $7 \cdot 3$ & 88 \\
\hline
\end{tabular}

* Rate of amidase induction. Amidase units synthesized/mg. bacterial growth.

$\dagger$ Catabolite repressibility. The percentage repression of the rate of amidase synthesis induced by $10 \mathrm{~mm}-N$-acetylacetamide in pyruvate medium resulting from the addition of $10 \mathrm{~mm}$-succinate.

Table 3. Growth of Pseudomonas aeruginosa 8602 wild type and mutant strains on selective media

Growth after incubation for $48 \mathrm{hr}$ at $37^{\circ}$ is scored as follows: ++++ , colonies raised, usually with yellow fluorescent pigment; + , colonies very small or faint, no pigmentation; trace, very faint shadowy colonial growth. Details of media in methods section.

\begin{tabular}{ccccc} 
Mutant & \multicolumn{3}{c}{ Media containing } \\
$\begin{array}{c}\text { Succinate } \\
\text { strain }\end{array}$ & Acetamide & $\begin{array}{c}\text { Succinate } \\
+ \text { formamide } \\
+ \text { cyanoacetamide }\end{array}$ & $\begin{array}{r}\text { Succinate } \\
+ \text { lactamide }\end{array}$ \\
Wild type & ++++ & Trace & Trace & + \\
C 1 & ++++ & ++++ & ++++ & + \\
C 2 & ++++ & ++++ & + & + \\
C 5 & ++++ & ++++ & + & +++ \\
C 24 & ++++ & ++++ & + & + \\
F 1 & ++++ & ++++ & Trace & + \\
Am 1 & - & - & - & -
\end{tabular}

\section{Growth of mutants on selective media}

The constitutive and formamide-inducible mutants were distinguished from the wild type by their ability to grow on $\mathrm{S} / \mathrm{F}$ plates. Other selective media were devised which can be used to distinguish other mutant classes.

Cyanoacetamide completely represses amidase induction and growth in liquid acetamide medium (Brammar \& Clarke, 1964) but it was not possible to reach a sufficiently high ratio of cyanoacetamide to acetamide in solid medium to repress growth of the wild-type strain on plates. It was however possible to repress growth and amidase induction when the inducing amide was formamide. All the magno-constitutive mutants with the exception of $\mathrm{C} 24$ grew as well on succinate + formamide + cyanoacetamide agar (S/F/CN plates) as on $\mathrm{S} / \mathrm{F}$ plates. Growth of all the semi-constitutive mutants was delayed, and colonies took 4-5 days to develop whereas on $\mathrm{S} / \mathrm{F}$ 


\section{$P$. aeruginosa amidase regulator mutants}

plates they appeared in 24-48 hr. This suggests that growth of the semi-constitutive mutants on $\mathrm{S} / \mathrm{F}$ medium normally involves amidase induction. Growth of all the formamide-inducible mutants was repressed on $\mathrm{S} / \mathrm{F} / \mathrm{CN}$ plates; this medium could therefore be used to select the magno-constitutive mutants.

Lactamide is an inducing amide with an activity similar to that of propionamide. It was previously reported (Kelly \& Clarke, 1962) that it was not a substrate for the enzyme, but Kelly \& Kornberg (1964) found that a preparation of their partially purified enzyme had an activity of 23.8 units/mg. protein for lactamide as compared with 260 units $/ \mathrm{mg}$. protein for acetamide. We have used a minimal agar medium containing $1 \%(\mathrm{w} / \mathrm{v})$ succinate and $0.02 \%(\mathrm{w} / \mathrm{v})$ lactamide in mutant selection experiments. On this medium the wild type and almost all the regulator mutants grew very slowly, producing colonies in 5-7 days. Strain C 5 grew very well in $24-48 \mathrm{hr}$ and C 9 grew significantly faster than the other mutant strains. This phenotype appears to be correlated with decreased susceptibility to catabolite repression. Table 3 summarizes the growth characteristics of the mutants on these selective media.

\section{Genetic analysis by transduction}

Preliminary experiments with a lysate of bacteriophage F 116 propagated on the wild-type strain showed that the amidase gene could be transferred to seven amidasenegative $\left(\mathrm{Am}^{-}\right)$mutants. The number of amidase-positive $\left(\mathrm{Am}^{+}\right)$transductants obtained depended on the particular recipient used. The genetic character of constitutivity was also transferred by phage $\mathrm{F} 116$. Alysate prepared with mutant $\mathrm{C} 1$ and used to infect the inducible wild-type strain gave constitutive transductants on $\mathrm{S} / \mathrm{F}$ plates after incubation for $48 \mathrm{hr}$ at $37^{\circ}$. Transduction of the amidase and constitutivity markers occurred at similar frequencies (200 to 250 transductants $/ 10^{9}$ recipient bacteria).

When the phage lysate from mutant $\mathrm{C} 1$ was used to infect the amidase-negative mutant AM 9, transductants were obtained on both acetamide and S/F plates. The occurrence of approximately equal numbers of colonies on both media suggested that the gene which conferred constitutivity was closely linked to the amidase structural gene and that these two markers had been co-transduced. Phage propagated on the inducible wild-type strain gave transductants only on acetamide (AM) plates, i.e. only inducible transductants. Infection of other $\mathrm{Am}^{-}$mutants with the lysate prepared on mutant $\mathrm{C} 1$, followed by selection of $\mathrm{Am}^{+}$transductants on $\mathrm{AM}$ and $\mathrm{S} / \mathrm{F}$ plates, indicated 75$100 \%$ linkage of the constitutivity marker to the amidase marker. This close linkage was determined more accurately by selecting $\mathrm{Am}^{+}$transductants on $\mathrm{AM}$ plates and replicating to $\mathrm{S} / \mathrm{F}$ plates. When the transductants had also inherited constitutivity, they grew on $\mathrm{S} / \mathrm{F}$ plates after $48-\mathrm{hr}$ incubation at $37^{\circ}$. The results given in Table 4 show that 87 to $98 \%$ of the $\mathrm{Am}^{+}$transductants carried the constitutivity marker associated with the $\mathrm{C} 1$ donor. They also indicate that all $10 \mathrm{Am}^{-}$mutations were located in a small region of the bacterial chromosome. A lysate prepared on $\mathrm{C} 4$, another magno-constitutive mutant, gave identical linkage values (Table 4). Since all the $\mathrm{Am}^{-}$mutants behaved similarly with respect to their linkage to the constitutivity marker carried by mutants $\mathrm{C} 1$ and $\mathrm{C} 4$, further transduction experiments with the remaining constitutive mutants weremade with only two or three $\mathrm{Am}^{-}$recipient mutants. Table 5 gives the results for a number of magno-constitutive and semi-constitutive mutants. They all resembled mutants $\mathrm{C} 1$ and $\mathrm{C} 4$ in that the constitutivity and amidase markers were co-transduced giving linkage values of $80-100 \%$. 
After replicating $\mathrm{Am}^{+}$transductants to $\mathrm{S} / \mathrm{F}$ plates, the time necessary for colonies to appear varied from 1 to 5 days of incubation at $37^{\circ}$, depending on the constitutive mutant used as donor. For example, Am+ transductants obtained from mutant $\mathrm{C} 1$ as donor grew on S/F plates after $24 \mathrm{hr}$ while $\mathrm{Am}^{+}$transductants from a C 2 donor required 5 days of incubation after replicating. When $\mathrm{Am}^{+}$transductants were selected directly on $\mathrm{S} / \mathrm{F}$ plates, a similar variation was observed in the time taken before transductant colonies appeared. This slow growth of transductants occurred when the donor was a semi-constitutive mutant. It was therefore necessary to confirm that such transductants were constitutive, rather than wild-type inducible growing out of the

Table 4. Phage transduction from constitutive mutants to amidase negative mutants of Pseudomonas aeruginosa 8602

$\begin{array}{cccc}\begin{array}{c}\text { Donor strain } \\ \text { phage lysate }\end{array} & \begin{array}{c}\text { Recipient } \\ \text { strain }\end{array} & \begin{array}{c}\text { No. of Am } \\ \text { transductant } \\ \text { colonies } \\ \text { examined }\end{array} & \begin{array}{c}\text { Constitutive } \\ \text { transductants } \\ (\%)\end{array} \\ \text { C 1 Magno-constitutive } & \text { Am 1 } & 54 & 92 \\ \text { Am 2 } & 92 & 87 \\ \text { Am 3 } & 141 & 94 \\ \text { Am 4 } & 169 & 88 \\ \text { Am 5 } & 63 & 91 \\ \text { Am 6 } & 318 & 94 \\ \text { Am 7 } & 178 & 98 \\ \text { Am 8 } & 187 & 98 \\ \text { Am 9 } & 126 & 98 \\ \text { Am 10 } & 224 & 95 \\ \text { C 4 Magno-constitutive } & \text { Am 1 } & 40 & 88 \\ \text { Am 2 } & 100 & 95 \\ \text { Am 3 } & 124 & 98 \\ \text { Am 4 } & 106 & 98 \\ \text { Am 5 } & 127 & 98 \\ \text { Am 6 } & 187 & 94 \\ \text { Am 7 } & 130 & 94 \\ \text { Am 8 } & 152 & 97 \\ \text { Am 9 } & 143 & 99 \\ \text { Am 10 } & 84 & 96\end{array}$

background growth of $\mathrm{Am}^{-}$recipients. Single transductants colonies from either AM or $\mathrm{S} / \mathrm{F}$ plates were isolated and tested. Cross-feeding of inducible bacteria by constitutive bacteria occurred readily so that it was not possible to identify them simply by streaking on $\mathrm{S} / \mathrm{F}$ agar. The following procedure was adopted to detect the presence of the constitutivity marker in the $\mathrm{Am}^{+}$transductant. Single colonies were grown overnight in broth, the culture was then suitably diluted and a loopful added to a suspension of wild-type inducible bacteria $\left(10^{8} / \mathrm{ml}\right.$.) Samples $(0 \cdot 1 \mathrm{ml}$.) of the mixture were plated on $\mathrm{S} / \mathrm{F}$ plates and incubated at $37^{\circ}$. If $200-250$ colonies grew out of the background growth of wild-type bacteria after 1-4 days, it was concluded that the Am ${ }^{+}$transductant also carried the constitutivity marker of the donor. This test was applied to at least five transductants from each cross; it was also applied to all colonies which did not grow when replicated from AM to S/F plates. The results were always conclusive in distinguishing between constitutive and inducible $\mathrm{Am}^{+}$transductants. Transductants obtained by infecting Am- mutants with phage propagated on the wild-type 
inducible strain, produced only inducible $\mathrm{Am}^{+}$transductants which gave no detectable colonies in the wild-type background growth, even after 7 days of incubation.

Genetic analysis by transduction was also done with $\mathbf{F}$ mutants as donors. The method was the same as that used with the constitutive strains, but with the F mutants as donors growth on $\mathrm{S} / \mathrm{F}$ plates indicated that formamide-inducible and not constitutive transductants had been selected. The results given in Table 5 show that the character for formamide inducibility was also co-transduced at high frequency with the character for amidase production.

Table 5. Transduction of amidase structural and regulator genes in Pseudomonas aeruginosa 8602 mutants

\begin{tabular}{|c|c|c|c|c|}
\hline $\begin{array}{l}\text { Donor } \\
\text { strain } \\
\text { phage } \\
\text { lysate }\end{array}$ & Phenotype & $\begin{array}{l}\text { Recipient } \\
\text { strain }\end{array}$ & $\begin{array}{c}\text { No. of Am+ } \\
\text { trans- } \\
\text { ductant } \\
\text { colonies } \\
\text { examined }\end{array}$ & $\begin{array}{c}\text { Trans- } \\
\text { ductants } \\
\text { growing } \\
\text { on } S / F^{*} \\
\text { plates }(\%)\end{array}$ \\
\hline $\left.\begin{array}{l}\mathrm{C} 8 \\
\mathrm{C} 9 \\
\mathrm{C} 10\end{array}\right\}$ & Magno-constitutive & $\left\{\begin{array}{l}\text { Am 9 } \\
\text { Am 10 } \\
\text { Am 7 } \\
\text { Am 10 } \\
\text { Am 9 } \\
\text { Am 10 }\end{array}\right.$ & $\begin{array}{l}194 \\
268 \\
105 \\
100 \\
183 \\
257\end{array}$ & $\begin{array}{l}96 \\
92 \\
92 \\
93 \\
99 \\
99\end{array}$ \\
\hline $\left.\begin{array}{l}C 2 \\
C 5 \\
C 20\end{array}\right\}$ & Semi-constitutive & $\left\{\begin{array}{l}\text { Am } 7 \\
\text { Am } 10 \\
\text { Am } 9 \\
\text { Am 10 } \\
\text { Am 7 } \\
\text { Am 10 }\end{array}\right.$ & $\begin{array}{r}68 \\
109 \\
143 \\
290 \\
246 \\
244\end{array}$ & $\begin{array}{l}97 \\
97 \\
88 \\
93 \\
97 \\
95\end{array}$ \\
\hline $\left.\begin{array}{l}F \quad 1 \\
F 2 \\
F\end{array}\right\}$ & Formamide-inducible & $\left\{\begin{array}{l}\text { Am 7 } \\
\text { Am 10 } \\
\text { Am 7 } \\
\text { Am 16 } \\
\text { Am 7 } \\
\text { Am 10 }\end{array}\right.$ & $\begin{array}{r}242 \\
161 \\
84 \\
206 \\
237 \\
266\end{array}$ & $\begin{array}{l}94 \\
93 \\
89 \\
91 \\
96 \\
96\end{array}$ \\
\hline
\end{tabular}

\section{DISCUSSION}

The regulator mutants of Pseudomonas aeruginosa 8602 can be classified phenotypically by their response to the various substrate and inducer amides, in terms of enzyme production and enzyme activity. The amidase-negative mutants do not grow on acetamide or any other substrate amide and do not produce an active amidase under any conditions. We have assumed provisionally that they all have mutations in the structural gene which determine the amidase protein. We are investigating these further by more detailed genetic mapping and by testing for the production of mutant protein without enzymic activity.

Most of the constitutive mutants can be assigned to the group described by Collins et al. (1965) as 'strictly constitutive, induction ratio $1 \cdot 0$, subgroup (a) magno-constitutive'. This appears to be the most common class of constitutive mutant isolated in other systems, e.g. Bacillus licheniformis penicillinase (Dubnau \& Pollock, 1965). One mutant, C 24, of Pseudomonas aeruginosa 8602 which was classed as magno- 
constitutive from its rate of amidase synthesis in succinate medium in the absence of inducer, had an induction ratio of 0.3 when tested with $\mathrm{N}$-acetylacetamide. Collins et al. (1965) discussed the possibility of the occurrence of this type of mutant, repressible by the normal inducer, and suggested that it should be considered with the class of repressible enzyme systems. We think that this would give a misleading impression of a mutant derived from a normally inducible enzyme system and prefer the description of magno-constitutive, inducer-repressible, for this strain. Jacob \& Monod (1963) referred to a class of partially constitutive $\beta$-galactosidase mutants repressible by galactosides which were inducers for the parent strain. The other group of amidaseconstitutive strains of $P$. aeruginosa 8602 are adequately described as semi-constitutive by using the nomenclature of Collins et al. (1965).

The mutants of Pseudomonas aeruginosa 8602 inducible by formamide are perhaps the most interesting and represent a mutant class which has not been previously described. They appear to have altered inducer specificity and a suitable general term to describe this phenotype would be 'neo-inducible' followed by an indication of the main change in inducer response, i.e. in our system 'neo-inducible, formamideinducible'. There was no obvious difference in experiments with intact bacteria between the amidase produced by these strains and that produced by the wild-type strain and it was therefore assumed that the genetic change was in the regulator gene and not the structural gene. These mutants might be predicted from the Jacob \& Monod (1961) theory of the regulation of enzyme synthesis. The mutations are probably in a regulator gene, resulting in the production of cytoplasmic repressor molecules with altered specificity towards the various amide inducers. By the same reasoning it is likely that the constitutive mutant $C 24$ of $P$. aeruginosa 8602 produces an altered cytoplasmic repressor which becomes effective in repressing amidase synthesis when combined with $N$-acetylacetamide, a non-substrate inducer for the wild-type strain. It is probable that the other magno-constitutive mutants are also regulator gene mutants in which the cytoplasmic repressor is altered or absent. The semi-constitutive mutants produce more enzyme in the presence of inducer than in its absence, and must therefore contain cytoplasmic repressor molecules which are capable of combining with the inducer. Our experiments cannot distinguish mutants of this phenotype which have mutations in a regulator gene ( $R$ mutants) from those which have mutations in an operator region (0 mutants). Linkage analysis from the results for co-transduction has shown that all the amidase regulator mutations are located in a small segment of the $P$. aeruginosa 8602 chromosome closely linked to the amidase structural gene. The amidase system therefore resembles the lac region of Escherichia coli where the R gene is closely linked to the structural genes (Jacob \& Adelberg, 1959) rather than the tryptophan synthetase system where the $\mathbf{R}$ gene is located on a distant segment of the bacterial chromosome (Cohen \& Jacob, 1959).

Regulator and operator-type mutations for $\beta$-galactosidase have been distinguished by examining the properties of diploids and by identifying operator mutations affecting the synthesis of the three separate proteins determined by the $\beta$-galactosidase operon, $\beta$-galactosidase, permease and transacetylase (Jacob \& Monod, 1961). We have not so far been able to make diploids for our Pseudomonas system and we have no evidence that more than one structural gene is concerned. Recently it was found that this strain of Pseudomonas aeruginosa produced a permease for aliphatic amides (Brammar et al. 1966), but this was constitutive and it is not known whether there is 


\section{P. aeruginosa amidase regulator mutants}

any linkage with the amidase genes. From transduction experiments with other mutants it was concluded that the amidase genes were not closely linked to genes which determined enzymes concerned with acetate metabolism, i.e. isocitrate lyase, acetyl-CoA synthetase and citrate synthetase.

Amidase synthesis by the wild-type strain Pseudomonas aeruginosa 8602 is very sensitive to catabolite repression, which could be reversed both in growing cultures and in carbon-starved bacteria, by increasing the inducer concentration (Brammar \& Clarke, 1964; Clarke \&Brammar, 1964). Most of the amidase constitutive mutants were also sensitive to catabolite repression and like the inducible strains had a maximum rate of amidase production in pyruvate medium at least three times higher than that in succinate medium. This suggests that succinate is a better source than pyruvate of the actual co-repressor molecule. It was shown in other systems that the addition of metabolic inhibitors such as 2,4-dinitrophenol (Mandelstam, 1961) or the introduction of anaerobic conditions (Cohn \& Horibata, 1959) released the synthesis of several enzymes from repression; several degradative enzymes (e.g. amino-acid decarboxylases Gale, 1946) are produced only at the end of growth as the metabolic rate decreases. The addition of azide stimulated amidase synthesis both by the wild-type strain of $P$. aeruginosa 8602 and by the constitutive mutant $C 1$, probably by decreasing the metabolic rate and the availability of the usual catabolite co-repressor.

If catabolite repression is in any way related to the activity of the cytoplasmic repressor produced by the regulator gene it should be reversed by the inducer. This reversibility is now established for $\beta$-galactosidase in Escherichia coli (Clark \& Marr, 1964; Moses \& Prevost, 1966) and the enzymes of the mandelate pathway in Pseudomonas fluorescens (Mandelstam \& Jacoby, 1965) as well as for $P$. aeruginosa amidase. It should also be possible to isolate regulator gene mutants with altered catabolite repressibility. McFall (1964) described several mutants for D-serine deaminase in $E$. coli which were partially constitutive and had altered sensitivity to catabolite repression. One magno-constitutive amidase mutant of $P$. aeruginosa 8602 had decreased sensitivity to catabolite repression and since it was also repressed by $\mathrm{N}$ acetylacetamide it seems reasonable to suppose that it produced a cytoplasmic repressor which had altered response to the normal inducer. Several of the semiconstitutive mutants of $P$. aeruginosa 8602 had altered catabolite repressibility and mutant $\mathrm{C} 5$ was repressed by succinate only in the presence of aninducer. Repression by succinate in the amidase system of $P$. aeruginosa 8602 has been shown to be quite different from the competitive repression by amide analogues such as cyanoacetamide (Clarke \& Brammar, 1964) so that there is no possibility here of succinate competing with the inducer as Loomis \& Magasanik (1966) suggested for galactose repression of $\beta$-galactosidase.

We suggested previously that the cytoplasmic repressor could be directly involved in catabolite repression by being able to combine with both inducer and catabolite co-repressor molecules with opposite effect (Clarke \& Brammar, 1964). The results of Loomis \& Magasanik $(1964,1965,1966)$ and Moses \& Prevost (1966) indicate that the mechanism may be more complex. A complete explanation of catabolite repression would depend on a fuller understanding of the molecular events which lead through transcription of genetic information of the DNA into RNA messengers to translation into specific proteins. 
We are grateful to the Medical Research Council for a grant in support of this work and A.J.S. is indebted to the Science Research Council for a Research Studentship.

\section{REFERENCES}

Adams, M. H. (1959). Bacteriophages. New York: Interscience Publishers.

Brammar, W. J. \& Clarke, P. H. (1964). Induction and repression of Pseudomonas aeruginosa amidase. J. gen. Microbiol. 37, 307.

Brammar, W. J., McFarlane, N. D. \& Clarke, P. H. (1966). The uptake of aliphatic amides by Pseudomonas aeruginosa. J. gen. Microbiol. 44, 303.

ClARK, D. J. \& MARR, A. G. (1964). Studies on the repression of $\beta$-galactosidase in Escherichia coli. Biochim. biophys. Acta 92, 85.

Clarke, P. H. \& BRAmmaR, W. J. (1964). Regulation of bacterial enzyme synthesis by induction and repression. Nature, Lond. 203, 1153.

Clarke, P. H. \& Brammar, W. J. (1965). Inducible and constitutive synthesis of Pseudomonas aeruginosa amidase. Abstr. 2nd Meet. Fed. Europ. Biochem. Soc. Vienna, A 8.

COHEN, G. N. \& JACOB, F. (1959). Sur la répréssion de la synthèse des enzymes intervenant dans la formation du tryptophane chez Escherichia coli. C.r. hebd. Séanc. Acad. Sci. Paris 248, 3490.

Cohn, M. \& Horibata, K. (1959). Physiology of the inhibition by glucose of the induced synthesis of the $\beta$-galactosidase-enzyme system of Escherichia coli. J. Bact. 78, 624.

Collins, J. F., Mandelstam, J., Pollock, M. R., Richmond, M. H. \& Sneath, P. H. A. (1965). A suggested phenotypic classification and terminology for enzyme mutants in micro-organisms. Nature, Lond. 208, 841.

Dubnau, D. A. \& Pollock, M. R. (1965). The genetics of Bacillus licheniformis penicillinase: a preliminary analysis from studies on mutation and interstrain and intra-strain transformations. J. gen. Microbiol. 41, 7.

Gale, E. F. (1946). The bacterial amino acid decarboxylases. Adv. Enzymol. 6, 1.

Holloway, B. W., Egan, J. B. \& Monk, M. (1960). Lysogeny in Pseudomonas aeruginosa. Aust. J. exp. Biol. med. Sci. 38, 321.

Holloway, B. W., MonK, M., Hodgins, L. \& FARGIE, B. (1962). Effects of radiation on transduction in Pseudomonas aeruginosa. Virology 18, 89.

JACOB, F. \& ADELBERG, E. A. (1959). Transfer de caractères génétique par incorporation au facteur sexuel d'Escherichia coli. C.r. hebd. Séanc. Acad. Sci., Paris 249, 189.

JACOB, F. \& MONOD, J. (1961). Genetic regulatory mechanisms in the synthesis of proteins. J. mol. Biol. 3, 318.

JACOB, F. \& MONOD, J. (1963). In Cytodifferentiation and Macromolecular structure, p. 30. Ed. by M. Locke. New York: Academic Press Inc.

Kelly, M. \& ClaRke, P. H. (1962). An inducible amidase produced by a strain of Pseudomonas aeruginosa. J. gen. Microbiol. 27, 316.

Kelly, M. \& KORNBERG, H. L. (1962). Discontinuity of amidase formation by Pseudomonas aeruginosa. Biochim. biophys. Acta 59, 517.

Kelly, M. \& Kornberg, H. L. (1964). Purification and properties of acyltransferase from Pseudomonas aeruginosa. Biochem. J. 93, 557.

LEDERBERG, J. \& LEDERBERG, E. M. (1952). Replica plating and indirect selection of bacterial mutants. J. Bact. 63, 399.

LOOMIS, W. F. \& MAGASANIK, B. (1964). The relation of catabolite repression to the induction system for $\beta$-galactosidase in Escherichia coli. J. mol. Biol. 8, 417.

Loomis, W. F. \& MaGasanik, B. (1965). Genetic control of catabolite repression of the Lac operon in Escherichia coli. Biochem. biophys. Res. Comm. 20, 230.

Loomis, W. F. \& MAGASANIK, B. (1966). Nature of the effector of catabolite repression of $\beta$-galactosidase in Escherichia coli. J. Bact. 92, 170.

MANDELSTAM, J. (1961). Induction and repression of $\beta$-galactosidase in non-growing Escherichia coli. Biochem. J. 79, 489.

MANDELSTAM, J. \& JACOBY, G. A. (1965). Induction and multi-sensitive end-product repression in the enzymic pathway degrading mandelate in Pseudomonas fluorescens. Biochem. J. 94, 569.

MCFALL, E. (1964). Pleiotropic mutations in the D-serine deaminase system of Escherichia coli. $J$. mol. Biol. 9, 754.

Moses, V. \& Prevost, C. (1966). Catabolite repression of $\beta$-galactosidase synthesis in Escherichia coli. Biochem. J. 100, 336.

Skinner, A. J. \& Clarke, P. H. (1965). C 2 mutants of Pseudomonas aeruginosa. J. gen. Microbiol. 39, viii.

Stanier, R. Y., Palleroni, N. J. \& Doudoroff, M. (1966). The aerobic pseudomonads: a taxonomic study. J. gen. Microbiol. 43, 159. 